\title{
Stimulus competition in the absence of compound conditioning
}

\author{
HELENA MATUTE and OSKAR PINEÑO \\ Universidad de Deusto, Bilbao, Spain
}

\begin{abstract}
Most associative theories have assumed that stimulus competition occurs only between conditioned stimuli (CSs) that are trained in compound. The present research investigated the possibility of competition between two CSs that were individually paired to the same unconditioned stimulus (US). We used human subjects in an anticipatory suppression analogue to Pavlovian conditioning. Experiment 1 showed that $\mathrm{X}+$ training followed by $\mathrm{A}+$ training resulted in impaired responding to $X$. This did not occur when $A+$ training preceded $X+$ training. Experiment 2 replicated the basic effect and showed that it did not occur when the Phase 2 training consisted of $A-$ instead of $A+$ nor when the $A+$ pairings occurred in a second context. Experiment 3 showed that A+ pairings occurring in a second context could still produce the effect when $X$ was tested in the context in which the $\mathrm{A}+$ pairings had occurred, but not when $\mathrm{X}$ was tested in a context different from that used for $\mathrm{A}+$ training. Collectively, these results suggest that individually trained CSs may compete with each other when one of those CSs is more strongly activated by the test context than the other one.
\end{abstract}

One of the best known findings in conditioning research is that if a conditioned stimulus (CS) is a very good predictor of an unconditioned stimulus (US), the conditioned response elicited by other CSs that are trained in compound with the good predictor will be impaired. This effect is often called stimulus competition, or cue selection. A typical example is the forward-blocking effect (Kamin, 1968), in which a CS, A, is paired to the US during Phase 1 (i.e., $A+$ ), and then, in Phase 2, $A$ is presented in compound with a novel CS, $X$, and followed by the US (i.e., $\mathrm{AX}+$ ). This results in weaker responding to the target cue $\mathrm{X}$ in a subsequent test phase relative to responding by control subjects that were not exposed to the A+ pairings in Phase 1 . There are many other designs through which stimulus competition effects have been observed (e.g., Wagner, Logan, Haberlandt, \& Price, 1968), but all of them have included compound training of the good predictor and the target cue. Consequently, despite many important discrepancies among the theories that attempt to explain these effects, all of them depend on the AX compound training as essential for $A$ influencing responding to X (e.g., Mackintosh, 1975; Miller \& Matzel, 1988;

Support for this research was provided by Grant PI96/006 from Departamento de Educación, Universidades, e Investigación (Basque Government), and Grant PB95-0440 from Dirección General de Enseñanza Superior (Spanish Ministry of Education) to H.M. The authors thank Anthony Dickinson, Martha Escobar, Ottmar Lipp, Ralph Miller, Nuria Ortega, and Sonia Vegas for their insightful comments on an earlier version of the manuscript, and Robert Boakes and Michael Young for very helpful discussions. The authors would also like to thank Kerstin Kindling for assistance in running pilot subjects for Experiment 2. Correspondence should be addressed to $H$. Matute, Departamento de Psicología, Universidad de Deusto, Apartado 1, 48080 Bilbao, Spain (e-mail: univem05@sarenet.es).
Pearce \& Hall, 1980; Rescorla \& Wagner, 1972). That is, according to most theories, if $\mathrm{X}$ were not trained in compound with $A$, responding to $X$ would not be impaired. The purpose of this research was to test this assumption.

Our basic paradigm consisted of a simplification of the typical forward blocking and backward blocking treatments, so that cue A would not be presented in compound with X. (Backward blocking consists of reversing the order of the two training phases of forward blocking; Shanks, 1985.) Thus, in our paradigm, Group Forward Competition was exposed to $\mathrm{A}+$ in Phase 1 and to $\mathrm{X}+$ (rather than $\mathrm{AX}+$ ) in Phase 2 and was then tested on $\mathrm{X}$. Group Backward Competition received the same treatment except that the two training phases were conducted in the reverse order.

The predictions of various theories for those two groups are quite clear. According to traditional associative theories, no competition between $A$ and $X$ should be observed in either case. Nevertheless, because the context is trained in compound with both $\mathrm{A}$ and $\mathrm{X}$, if the context acquired strong associative strength, these theories would predict either exclusively forward blocking by context (e.g., Mackintosh, 1975; Pearce \& Hall, 1980; Rescorla \& Wagner, 1972) or similar degrees of forward and backward blocking by context (e.g., Miller \& Matzel, 1988; Shanks \& Dickinson, 1987). Thus, if competition were stronger in the forward case, or if similar degrees of responding were observed regardless of trial order, the experiment would not speak to the issue of competition between individually trained CSs. Moreover, several nonassociative (rule-based) models would also predict impaired responding to $\mathrm{X}$ in the two groups, regardless of trial order, not because of associative interference but because of the identical statistical contingency to which the two groups are exposed (e.g., Allan, 1980; Busemeyer, Myung, \& 
McDaniel, 1993; Cheng \& Novick, 1992). Thus, in the first experiment, we tested for potential trial order effects (i.e., forward vs. backward competition) because, as shown below, only if competition were stronger in the backward condition would our results be indicative of competition between individually trained CSs.

Although the possibility of stronger competition in the backward case may seem, at first glance, inconsistent with contemporary theories of learning, there are several recent revisions of Rescorla and Wagner's (1972) model that can be interpreted as making such a prediction (see Dickinson \& Burke, 1996; Markman, 1989; Tassoni, 1995; Van Hamme \& Wasserman, 1994). These models predict that if an expected CS is omitted in a given trial, the representation of that CS becomes negatively activated, and this produces "unlearning" of its associative strength. Thus, if we interpret $X$ as an absent $\mathrm{CS}$ that is expected during the $\mathrm{A}+$ pairings in our backward (but not forward) condition, these models predict that $X$ should lose associative strength during each of the A+ pairings in the backward condition.

For example, the model that Van Hamme and Wasserman (1994) have proposed is formally identical to that of Rescorla and Wagner (1972), except that it allows for the processing of stimuli that are absent in a given trial. According to Rescorla and Wagner, changes in the associative strength of a CS X, $\Delta V x$, occur on any learning trial in which $\mathrm{X}$ is present according to the following equation:

$$
\Delta V x=\alpha \cdot \beta \cdot(\lambda-\Sigma V),
$$

where $\lambda$ is the associative potential of the US (which takes a value of 0 if the US is absent and a positive value if the US is present on the trial), $\Sigma V$ is the sum of the associative strength of all of the CSs that are present in that trial, $\beta$ is a learning rate parameter of the US (which takes a value between 0 and 1 if the US is present and a smaller value, between 0 and $l$ as well, if the US is absent), and $\alpha$ is the salience of the CS (which takes a value of 0 if the CS is absent and a value between 0 and 1 if the CS is present). The modification that Van Hamme and Wasserman introduced consists of allowing a nonzero (negative) value for $\alpha$ on trials on which an expected CS is absent. This produces unlearning of the associative strength of such an absent-but-expected CS.

Because the different versions of the negative activation model have differed in their specification of which CSs among the multitude of absent CSs should be "expected" and become negatively activated, it is not entirely clear whether we should interpret $X$ as receiving such negative activation in our backward group. Some versions of this model have placed no specific constraints on the CSs that can become negatively activated and have assumed that any CS that is "relevant" in a given context (e.g., a CS that has previously acquired some associative strength in that context or that has been mentioned in the instructions of a human experiment) becomes negatively activated on trials in which it is not presented (Tassoni, 1995; Van Hamme \& Wasserman,
1994). If literally interpreted, these versions of the negative activation model would predict competition between the two individually trained CSs in our backward condition, with each of the A+ pairings of Phase 2 resulting in a reduction of the associative strength of $X$.

However, other versions (Dickinson \& Burke, 1996; Markman, 1989) would predict no reduction in the associative strength of $\mathrm{X}$ during the $\mathrm{A}+$ pairings, because they have explicitly included the constraint that only CSs that have a within-compound association to a CS that is present in a given trial can become negatively activated in that trial. This constraint has been included in order to better account for the data available in the literature. For example, experiments with humans have shown that effects similar to backward blocking occur when subjects receive consistent $\mathrm{AX}+$ pairings during Phase 1 (which presumably allow for the formation of within-compound associations between $A$ and $X$ ) but not in a control group in which $X$ is paired in an inconsistent manner with several different CSs during Phase 1 (Dickinson \& Burke, 1996). Similarly, backward-blocking experiments with rats have shown blocking in the backward-blocking group exposed to $\mathrm{AX}+$ followed by $\mathrm{A}+$, but not in the control group exposed to $\mathrm{AX}+$ followed by $\mathrm{C}+$, which is a condition in which a within-compound association between $\mathrm{X}$ and the blocking cue (in this case, C) cannot be formed (e.g., Miller \& Matute, 1996). As noted by Miller and Matute, whereas the within-compound versions of the negative activation model (e.g., Dickinson $\&$ Burke, 1996) can explain these results, the versions that lack this constraint (e.g., Van Hamme \& Wasserman, 1994) predict equal or even greater blocking in the control groups than in the experimental groups. For example, in Miller and Matute's control group ( $\mathrm{AX}+$ followed by $\mathrm{C}+$ ), the associative strength of $\mathrm{C}$ at the start of Phase 2 should be 0 , whereas the associative strength of $A$ at the start of Phase 2 in the experimental group should be greater than 0 . This, according to Van Hamme and Wasserman's model, should produce a greater reduction of the associative strength of $\mathrm{X}$ in the control group than in the experimental group. By contrast, the within-compound version (Dickinson \& Burke, 1996) predicts no blocking in the control group, because $C$ would not activate the representation of a cue with which it has not been previously paired. Thus, within-compound associations between the blocking and the to-be-blocked cue appear necessary in the framework of the negative activation models in order to explain the data available on retrospective revaluation effects.

In sum, there is reason to believe that $A$ and $X$ will not compete in our noncompounded paradigm, because a within-compound association cannot be formed between them. (Of course, we could assume that within-compound associations formed between $\mathrm{X}$ and the context during Phase 1 could serve the purpose of negatively activating the representation of $\mathrm{X}$ during Phase 2; however, in that case, the within-compound version would no longer be able to provide an explanation for the experiments for 
which it was created [e.g., Dickinson \& Burke, 1996].) However, and despite this reasonable prediction, we decided to test for competition between individually trained cues, because the results of some failed experiments on backward blocking in our laboratory suggested that, sometimes, $\mathrm{C}$ might be competing with $\mathrm{X}$ in the control groups, which would indicate that competition between noncompounded cues was possible. The present research used human subjects in an anticipatory suppression preparation analogue to Pavlovian conditioning to test for this possibility.

\section{EXPERIMENT 1}

In Experiment 1, we simplified the typical forwardand backward-blocking procedures in order to test which of those procedures produced the strongest, if any, stimulus competition in the absence of compound trials. Group Forward Competition was exposed to $\mathrm{A}+$ in Phase 1 and to $\mathrm{X}+$ in Phase 2 (rather than to the typical forwardblocking training that consists of $\mathrm{AX}+$ during Phase 2 ). Group Forward Control received equivalent training on $\mathrm{X}+$ during Phase 2 but received only context exposure (with no CSs or US presentations) during Phase 1. For Groups Backward Competition and Backward Control, the order of those two phases was reversed. At test, all groups were tested on $\mathrm{X}$. Therefore, our forward and backward conditions were analogous to standard forward- and backward-blocking experiments, respectively.

\[ \text { Method } \]
Subjects
Fifty-two undergraduate psychology students volunteered for
the experiment. The subjects were randomly assigned in approxi-
mately equal number to the forward competition $(n=13)$, forward
control $(n=14)$, backward competition $(n=13)$, and backward
control $(n=12)$ groups.

\section{Design}

Table 1 summarizes the design for this experiment. Group Forward Competition was exposed to $\mathrm{A}+$ during Phase 1 and to $\mathrm{X}+$ during Phase 2, whereas the order of these two phases was reversed for Group Backward Competition. The two control groups received only context exposure (with no CS or US presentations) during the corresponding blocking phase (i.e., Phase 1 for Group

Table 1

Design Summary of Experiment 1

\begin{tabular}{lllc}
\hline & \multicolumn{2}{c}{ Treatment } & \\
\cline { 2 - 3 } \multicolumn{1}{c}{ Group } & Phase 1 & Phase 2 & Test \\
\hline Forward competition & $\mathrm{A}+/ \mathrm{B}-$ & $\mathrm{X}+/ \mathrm{C}-$ & $\mathrm{X}$ \\
Forward control & Context & $\mathrm{X}+/ \mathrm{C}-$ & $\mathrm{X}$ \\
Backward competition & $\mathrm{X}+/ \mathrm{C}-$ & $\mathrm{A}+/ \mathrm{B}-$ & $\mathrm{X}$ \\
Backward control & $\mathrm{X}+/ \mathrm{C}-$ & Context & $\mathrm{X}$ \\
\hline
\end{tabular}

Note- $A$ and $X$ were the critical CSs and were yellow and blue, counterbalanced; $\mathrm{B}$ and $\mathrm{C}$ were two distractor stimuli that were included to prevent strong stimulus generalization (see Design section). These stimuli were brown and red, counterbalanced. Presentations of $A$ and $\mathrm{X}$ were always followed by the US, whereas presentations of $\mathrm{B}$ and $\mathrm{C}$ were never reinforced.
Forward Control, and Phase 2 for Group Backward Control). Additionally, some distractor stimuli, B and $C$, which were never paired with the US, were inserted in both the forward and the backward conditions (see Table 1). The addition of distractors is common practice in human research. Whereas subjects in a typical animal experiment are exposed to many arousing cues (novel contextual and accidental stimuli) in addition to the critical stimuli under study, the excessive simplicity of the computer-based tasks typically used in human research requires that some distractors be explicitly included in order to prevent stimulus generalization that would mask the effect of interest and result in strong responding to all cues. All four groups were tested on $X$.

\section{Apparatus}

The experiment was run using personal computers, with the subjects responding on keyboard. The computers were located in a laboratory, which allowed for simultaneous running of all subjects. The subjects were seated about $1.5 \mathrm{~m}$ apart, and each subject was exposed to an experimental condition (and counterbalancing of stimuli) different from that for the 2 adjacent subjects.

The task was an adaptation of a behavioral preparation for use with humans that was recently developed by Arcediano, Ortega, and Matute (1996). This preparation uses a video game and an aversive US that is given motivational value through instructions. Changes in the background color of the screen serve as CSs, and a Martian invasion within the video game substitutes for the footshock US typically used in aversively motivated research with animals. The critical finding in Arcediano et al.'s study was that humans showed increasing suppression of ongoing responding in the presence of the CSs that predicted the US, but not in the presence of the CSs that predicted the absence of the US. This task has also been shown to be a reliable preparation in the study of other wellknown effects, such as traditional (i.e., compounded) forward blocking (Arcediano, Matute, \& Miller, 1997). In the present research, we used this preparation to assess whether individually trained CSs would compete in coming to suppress ongoing responding.

\section{Procedure}

Pretraining. The purpose of the pretraining phase was to teach each subject to barpress consistently using the space bar of the computer keyboard. No CSs or USs were presented during this phase. The screen showed Martians that were trying to invade the Earth, and the goal of the subjects was to prevent their landing by shooting a gun at them. The instructions used for this phase, translated from Spanish, read as follows:

Your task is to prevent Martians from landing. Every half second one new Martian will try to land. In order to destroy them, you must use your laser-gun (the space bar) before they can see you, that is, just before you can see them. But do not shoot too early because you only have one shot per Martian. At the end of this phase, we will tell you the percentage of Martians that you have killed. THE PLANET DEPENDS ON YOU!! DO NOT ALLOW THEM TO LAND!!

The left panel of Figure 1 represents a typical screen during the pretraining phase. Martians were represented by ASCII 002 ( $\odot)$ in graphics mode and were approximately $7 \mathrm{~mm}$ in diameter. They appeared horizontally at intervals of $0.3 \mathrm{sec}$ on a black background, with a space of approximately $14 \mathrm{~mm}$ separating each Martian from the previous one. If the subject pressed the space bar before a Martian was displayed, an explosion (represented by ASCII 015 [ ] with the same format), rather than a Martian, was displayed. The objective was to have the screen filled with explosions, rather than Martians. Only one barpress per Martian was allowed. If more than one press was recorded (e.g., if the subject held the space bar pressed down), a Martian, rather than an explosion, was displayed. The screen was filled when 80 Martians or explosions ( 10 in each of 8 lines) had been displayed, but no breaks be- 

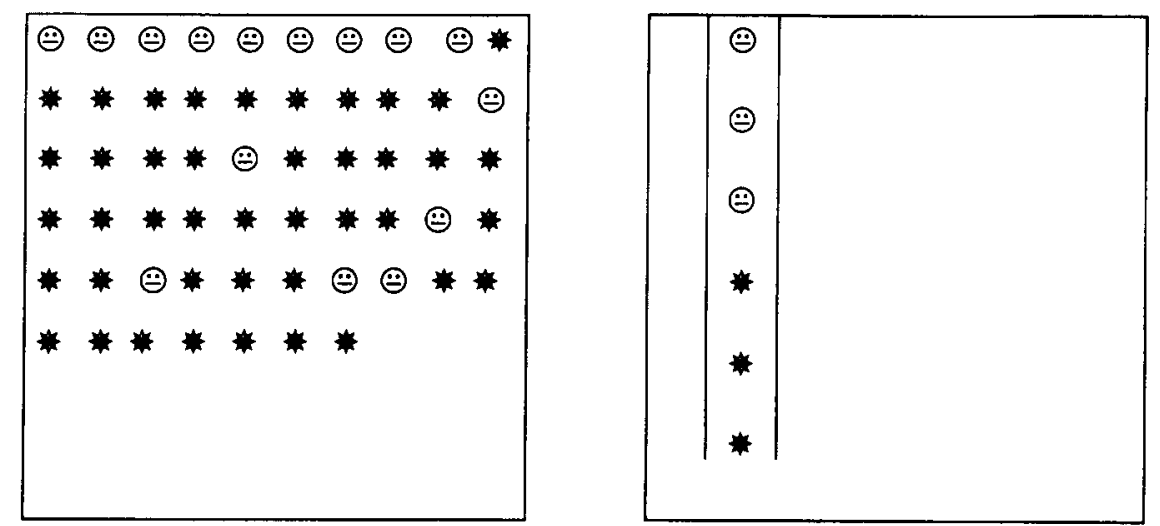

Figure 1. The left panel shows a screen with the horizontal context, and the right panel shows a screen with the vertical context. Experiment 1 used the horizontal context. In Experiments 2 and 3, the horizontal context and the vertical context, counterbalanced, served as Contexts 1 and 2.

tween screens appeared. Instead, when the screen was filled, it moved up, 1 line at a time, to make room for new Martians. One hundred Martians were depicted as attempting to land during this phase. All of this was first demonstrated by one of the experimenters, who explained and performed the pretraining phase on a computer that was connected to a large screen that could be seen by all subjects. Any questions were answered aloud. Next, each subject completed the pretraining phase, which ended with the score (percentage of explosions) displayed on a cleared screen.

Phases 1 and 2. Phases 1 and 2 consisted of the critical Pavlovian training, which was superimposed on the operant baseline task. That 1s, the CSs and USs were presented during performance of the Martian task. Immediately after pretraining was complete, the subjects were asked to go to the next screen by pressing "enter," read that screen carefully, and wait until all of the subjects had read it. This screen contained the following instructions (in Spanish):

\begin{abstract}
Now the Martians have developed a powerful ant1-laser shield. You must continue using your laser to prevent their landing. BUT BE CAREFUL because if you shoot your laser gun when the shield is connected, your shot will reflect back to you, thousands of Martians will land safely immediately, and you no longer will be able to avold that invasion. You will know that the shield is connected when you see a WHITE INTERMITTENT FLASHING on the screen.
\end{abstract}

Now, Martians appeared at $0.2-\mathrm{sec}$ intervals. The US was a white flashing screen (12 flashes/second) presented for $0.4 \mathrm{sec}$ if no response was made during its presentation. But if a response was recorded during the US, the flashes remained on for an additional 3-sec period, during which Martians invaded the screen (at a rate of 20, rather than 10, Martians per line, and a betweenMartians spacing of $7 \mathrm{~mm}$ ). The experimenter used a demonstration variant of the program that contained only two trials to show the subjects the difference between a short (without punishment) and a long (punishing) US. No CSs were presented during this demonstration. As in the pretraining phase, the experimenter's screen could be seen by all subjects. Additionally, all subjects were verbally instructed that some of them would be exposed to frequent USs (i e., shields), that others would spend long periods of time with no USs being presented, and that others would never at all be exposed to USs (although, in fact, no subject was exposed to a condition in which USs never appeared). This was done because pilot work had shown that if all subjects were run simultaneously (with all of them receiving the same instructions and demonstration on USs), control subjects exposed to a long period of time with no CS or US presentations tended to interrupt their performance because they thought that their computer was not workıng properly. After this demonstration on USs was complete, the subjects were asked to read the following instructional screen:

Some INDICATORS will help you predict when the shield is about to be connected, but there will also be some irrelevant cues. If you learn to distinguish between the valid and the irrelevant indicators, you will always be able to avoid the shield. Otherwise, every time that the Martrans connect the shield (white flashing light), they will catch you shooting and thousands of them will invade

Remember, just one shot while the shield is connected (WHITE FLASH) and the Martians will invade

After the subjects read these instructions, the experimenter told them the password that they needed to go on to the next screen (which was used so that all subjects would start and finish at the same tıme), and the subjects started the experiment.

CSs $\mathrm{A}$ and $\mathrm{X}$ were yellow and blue backgrounds, counterbalanced; CSs B and C were red and brown backgrounds, counterbalanced. CS duration during Phases 1 and 2 was 1 sec The background color remained black during the intertrial intervals (ITIs). The duration of the ITI was pseudorandom, with a range between 6 and $12 \mathrm{sec}$, and a mean of $9 \mathrm{sec}$. Barpresses continued to be remforced by explosions during the ITIs as well as during the presentations of the CSs. Only responses that occurred during the presentations of the US (white flashing light) were punished by a Martian invasion.

During Phase 1, Group Forward Control was exposed to the experimental context, with no CSs or USs being presented; this group performed only the operant (Martians) task. Group Forward Competition received 20 Pavlovian trials that were superimposed on the operant task in pseudorandom order: 10 of these trials consisted of CS A followed immediately by the US, and 10 consisted of CS B not followed by the US. During Phase 2, these two groups recelved 20 trials in the same pseudorandom order as Phase 1: 10 trials consisted of CS X followed by the US, and 10 consisted of CS $\mathrm{C}$ not followed by the US. These two phases occurred without interruption. Groups Backward Control and Backward Competition were exposed to the identical treatment except that the order of phases was reversed (see Table 1).

Test Phase. A 15-sec ITI separated the last Phase 2 trial from the test phase. The test phase was identical for all subjects: $\mathrm{X}$ was presented once without reinforcement for $5 \mathrm{sec}$ while the subjects were still barpressing to shoot Martians. Presumably, if the subjects expected the US to occur after X, they would suppress responding in the presence of X On the other hand, if either forward or backward competition took place, the subjects would not expect 
the US after $X$ and, thus, should not suppress responding in the presence of this stimulus.

\section{Results and Discussion}

Weak suppression of barpressing to $\mathrm{X}$ was observed in Group Backward Competition compared with its control, but not in Group Forward Competition compared with its control. Thus, backward, but not forward, competition was obtained between individually trained CSs. That is, in the absence of compound training, the acquisition of a new CS-US association during Phase 2 can compete with the previously acquired association between the US and another CS.

A suppression ratio of the form $a /(a+b)$, where $a$ is the number of responses during the CS, and $b$ is the number of responses in an equal period of time immediately preceding the occurrence of the CS, was computed for the test trial with X. Figure 2 depicts mean conditioned responding to $X$ during the test trial for each group, as represented by its suppression ratio. A 2 (order: forward vs. backward) $\times 2$ (condition: competition vs. control) analysis of variance (ANOVA) on suppression ratios yielded no main effect for condition $[F(1,48)=0.22$, $p>.5]$ or order $[F(1,48)=2.98, p>.05]$. However, the order $\times$ condition interaction was significant $[F(1,48)=$ $6.42, p=.01]$. Planned comparisons found that competition occurred in Group Backward Competition relative to its control $[F(1,48)=4.35, p<.05]$, whereas Group Forward Competition tended (nonsignificantly) to respond more vigorously than its control $[F(1,48)=2.20$, $p>.1]$.

The results of the backward-control group indicate that the retention interval imposed by Phase 2 training was not responsible for the weak responding observed in Group Backward Competition. Thus, these results indicate that, in the absence of compound training, the ac-

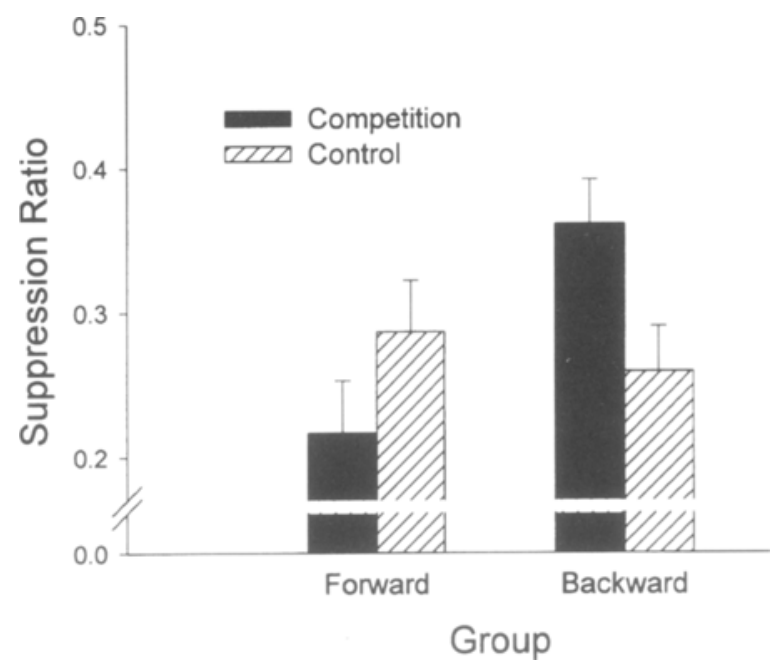

Figure 2. Conditioned responding to the target $\mathrm{CS}, \mathrm{X}$, during the test phase of Experiment 1 . The dependent variable was mean suppression ratio. Thus, a lower value indicates stronger conditioning. Error bars represent standard errors of means. quisition of a new CS-US association interfered with responding to a CS that was previously associated to the same US. This effect was seen only with the backward condition. The behavior of Group Forward Control indicated that there was no significant impairment or facilitation on Group Forward Competition as a result of its Phase 1 training. Moreover, the difference between Groups Forward Competition and Backward Competition $[F(1,48)$ $=9.10, p<.01]$ was replicated in an additional experiment in which we ran only those two groups. For brevity, we omit the details of that replication, but the results were very similar to the present ones. Consequently, the remaining part of this research focused on analyzing the backward-competition effect.

\section{EXPERIMENT 2}

The results of Experiment 1 showed that the acquisition of a new association (A-US) during Phase 2 can interfere with an association that was learned during Phase 1 (X-US). This suggests that competition can take place between stimuli that have not been trained in compound. But perhaps a simpler explanation that we should consider is that our effect was due to memory overload (i.e., a memory interference effect that could have been produced by any learning that occurred during Phase 2) rather than to associative interference. To control for this possibility, in Experiment 2, we introduced the following modifications. First, no distractor stimuli were used during Phase 2, and only Stimuli $A$ and $X$ were used. That is, instead of being exposed to $\mathrm{X}+/ \mathrm{C}-$ during Phase 1 and to $\mathrm{A}+/ \mathrm{B}-$ during Phase 2 , Group $\mathrm{A}+$ in this experiment received only $\mathrm{X}+/ \mathrm{A}-$ training in Phase 1 and $\mathrm{A}+$ training during Phase 2. This allowed us (1) to reduce the total number of stimuli involved and (2) to reduce the novelty of the stimulus used during Phase 2 . If the effect observed in Experiment 1 were due to memory overload (or to the novelty of A during Phase 2), it was expected to be reduced by these modifications. Alternatively, if the effect were due to associative interference, these changes were not expected to affect the result.

A second group in this experiment (Group A-) was also exposed to $\mathrm{X}+, \mathrm{A}-$ training Phase 1 but received $\mathrm{A}$ - training, instead of $\mathrm{A}+$, during Phase 2 , in order to test whether the mere repetition of $A$ during Phase 2 might be interfering with the recovery of $X$. Finally, a third group in this experiment received treatment identical to Group $\mathrm{A}+$ (i.e., $\mathrm{X}+, \mathrm{A}-$ followed by $\mathrm{A}+$ ), except that it received the $A+$ pairings of Phase 2 in a second context (Group A+Context2). If the effect were due to memory overload, it should still occur regardless of whether the $\mathrm{X}+$ and the $\mathrm{A}+$ pairings occur in the same context or in a different context. However, if the effect were due to associative interference, giving $\mathrm{A}+$ training in a context different from that in which $\mathrm{X}$ is trained and tested should probably reduce the effect. For example, as noted in the introduction, some interpretations of the negative activation model predict that the $\mathrm{A}+$ pairings in Phase 2 produce a negative activation of $X$ and, thus, 
a reduction of its associative strength. This negative activation of $X$ presumably takes place either through the within-compound association that was acquired during Phase 1 between $X$ and the context (e.g., Dickinson \& Burke, 1996) or because $X$ is a "relevant" cue in the context in which the A+ pairings occur (e.g., Van Hamme \& Wasserman, 1994). Thus, according to those models, if the A+ pairings of Phase 2 occurred in a different context, no reduction in the associative strength of $X$ should be expected. By contrast, an explanation in terms of memory overload would predict impairment regardless of whether the $\mathrm{A}+$ pairings occur in the same context or in a different context.

\section{Method}

\section{Subjects}

Thirty nonpsychology students from Deusto University volunteered for the study. The subjects were randomly assigned in approximately equal number to Groups $\mathrm{A}+, \mathrm{A}-$, and $\mathrm{A}+\mathrm{Context} 2$ ( $n s=11,11$, and 8 , respectively). None of the subjects had participated in Experiment 1.

\begin{abstract}
Apparatus
The apparatus was identical to that in Experiment 1 except that we now used two different contexts. Figure 1 shows the horizontal and vertical contexts, which, counterbalanced, served as Context 1 and Context 2 in this experiment. The horizontal context was the one used in Experiment 1. It consisted of Martians or explosions being added to horizontal rows on the computer screen. The new context consisted of a new manner of presenting the Martians and their explosions on the screen. In this new context, Martians and explosions were added in vertical columns going down, and they occupied only the left side of the screen (such as in the right panel of Figure 1), with the rest of the screen remaining black. Additionally, as can be seen in Figure 1, Martians (and explosions) were surrounded by a vertical line on each side. All other details, such as the between-Martians time intervals and the presentation of the CSs and USs, were identical in the two contexts. Blue and yellow backgrounds, counterbalanced, served as CSs A and X.

\section{Procedure}

The procedure was identical to that in Experiment 1 except as otherwise noted. A design summary is presented in Table 2 . The experimenter told the subjects that each of them had been assigned to one of two different Martians games (one with a vertical aspect, the other one with a horizontal aspect) and demonstrated the pretraining phase using the two different games (i.e., the two different contexts) that could serve as Context 1 . Next, the subjects completed their own pretraining. The pretraining phase, as well as Phase 1, took place in Context 1 (either vertical or horizontal) for each subject. Phase 1 was identical in the three groups and consisted of 8 presentations of $X$, which was always followed by the
\end{abstract}

Table 2

Design Summary of Experiment 2

\begin{tabular}{llll}
\hline \multirow{2}{*}{ Group } & \multicolumn{2}{c}{ Treatment } & \\
\cline { 2 - 4 } & Phase 1 & Phase 2 & Test \\
\hline $\mathrm{A}+$ & $(\mathrm{X}+/ \mathrm{A}-)_{1}$ & $(\mathrm{~A}+)_{1}$ & $(\mathrm{X})_{1}$ \\
$\mathrm{~A}-$ & $(\mathrm{X}+/ \mathrm{A}-)_{1}$ & $(\mathrm{~A}-)_{1}$ & $(\mathrm{X})_{1}$ \\
$\mathrm{~A}+$ Context2 & $(\mathrm{X}+/ \mathrm{A}-)_{1}$ & $(\mathrm{~A}+)_{2}$ & $(\mathrm{X})_{1}$ \\
\hline
\end{tabular}

Note- $A$ and $X$ were yellow and blue, counterbalanced; + represents the US, and - represents its absence; the subscripts 1 and 2 refer to Contexts 1 and 2 , respectively.
US, and 8 presentations of $A$, which was never followed by the US. The order of $\mathrm{X}+$ and $\mathrm{A}-$ trials was pseudorandom, with the same randomization occurring in all three groups. Phase 2 took place in Context 1 for Groups A + and A - and in Context 2 for Group $A+$ Context2. This phase consisted of 5 presentations of $A$, which was always followed by the US in Groups $A+$ and $A+C o n t e x t 2$, but was never followed by the US in Group A-. The test phase occurred in Context 1 for all three groups and consisted of one presentation of $X$.

Although other studies using this preparation in our laboratory (e.g., Arcediano et al., 1996) had shown that discriminative $X+/ A-$ training establishes differential stimulus control, we were uncertain of the effect that the new contextual manipulations and the absence of distractors during Phase 2 would have during the training phases in the present experiment. Thus, in this experiment, we added some assessment trials during the training phases. For this reason, the duration of the CSs during training, which had been kept constant at $1 \mathrm{sec}$ in Experiment 1, was varied between 1 and $2 \mathrm{sec}$ in this experiment. Specifically, the first and last trials for each CS in each phase were used as assessment trials and lasted $2 \mathrm{sec}$, with the duration of all other CSs being $1 \mathrm{sec}$

In addition to the above differences with respect to Experiment 1 , the following procedural changes were also implemented in this experiment with the intent of augmenting the sensitivity of our preparation: (1) the duration of CS X at test was reduced from $5 \mathrm{sec}$ in Experiment 1 to $3 \mathrm{sec}$ in this experiment, (2) the duration of the Martians' invasion if the subjects responded during the presentation of the white flash was increased from $3 \mathrm{sec}$ in Experiment 1 to $5 \mathrm{sec}$ in this experiment, (3) we now assessed the number of responses during the $3-\mathrm{sec}$ pre-CS interval at test, in addition to suppression ratios, in order to allow assessment of whether any differences in context conditioning and base rate behavior could be responsible for the observed differences, and (4) in order to warn the subjects of a potential context shift during the experiment, the following instructional screen was included immediately before the subjects started Phase 1 of training (i.e., immediately after the "indicators" instructional screen described in Experiment 1):

But, BE CAREFUL, because the Martians, after checking your defensive potential, could make use of a special combat group. This combat group may use new st rategies of invasion with which you might not be familiar.

Please, remember:

1. Your mission is to shoot them all. (But avoid that they catch you shooting when they connect the shield.)

2. If you learn to distinguish the correct indicators from the irrelevant ones, you will always be able to avoid the shield

3. It is possible that a new combat group which uses different strategies will appear from time to time. Don't let them deceive you.

\section{Results and Discussion}

Group $\mathrm{A}+$, which received the Phase $2 \mathrm{~A}+$ pairings in the same context that was used for $\mathrm{X}$ training and testing, showed weaker suppression to $X$ at test than the other two groups, which did not differ from each other. Thus, as in Experiment 1, A competed with X when A+ training was given in Phase 2. However, no competition was observed when A-training was given in Phase 2. Additionally, the effect was context specific; it did not occur when the $\mathrm{A}+$ pairings occurred in a context that was different from that used for $\mathrm{X}$ training and testing.

The results of greatest interest are shown in Figure 3, which depicts mean conditioning responding to $\mathrm{X}$ during the test phase for each group, as represented by suppression ratios. As can be seen in this figure, suppression of 


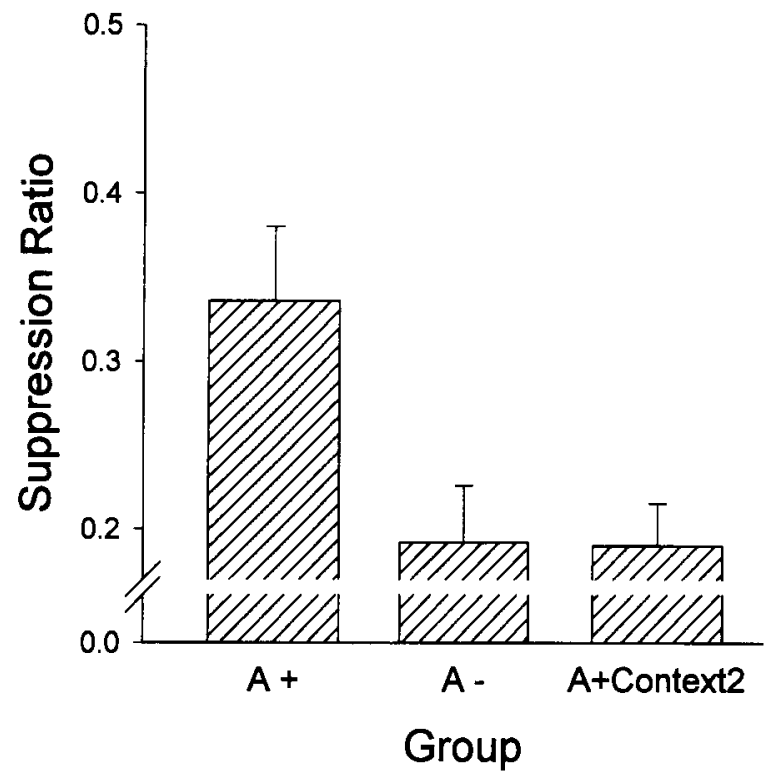

Figure 3. Conditioned responding to the target $\mathrm{CS}, \mathrm{X}$, during the test phase of Experiment 2 . The dependent variable was mean suppression ratio. Thus, a lower value indicates stronger conditioning. Error bars represent standard errors of means.

responding was stronger in Groups $\mathrm{A}-$ and $\mathrm{A}+\mathrm{Con}-$ text 2 than in Group A+. A one-way ANOVA on suppression ratios during the test phase yielded an overall group effect $[F(2,27)=5.25, p=.01]$, and planned comparisons confirmed that competition occurred in Group $\mathrm{A}+$ as compared with Group $\mathrm{A}+$ Context2 $[F(1,27)=$ $7.10, p=.01]$ and as compared with Group $\mathrm{A}-[F(1,27)=$ $8.20, p<.01]$. No differences were observed between Groups $\mathrm{A}+$ Context 2 and $\mathrm{A}-(p>.5)$.

An analysis of the number of responses during the 3sec pre-CS interval at test showed similar response rates for Group A $+(M=15.5, S E=0.52)$, Group A $-(M=$ $16, S E=0.48)$, and Group $\mathrm{A}+$ Context2 $(M=15.2$, $S E=0.44)[F(2,27)=0.71, p>.1]$, thereby indicating that differences during the pre-CS interval were not responsible for the differential suppression to $\mathrm{X}$ at test.

Data from the assessment trials that we introduced during the training phases of this experiment showed that, despite the procedural modifications that we introduced in this experiment, the subjects were sensitive to the treatment that they had received. A 3 (group) $\times 2$ (CS) ANOVA on suppression ratios from the last Phase 1 trial with each CS showed a main effect for CS (A or X) $[F(1,27)=171.42, p<.001]$, but no main effect for group nor interaction ( $p$ s $>.1$ ). That is, by the end of Phase 1, all three groups were suppressing responding to $\mathrm{X}$ but not to $\mathrm{A}$. Planned comparisons between $\mathrm{A}$ and $\mathrm{X}$ within each group also confirmed that all three groups were discriminating between $\mathrm{X}$ and $\mathrm{A}$ at the end of Phase $1[F(1,27)=71.85, p<.001$, for Group $\mathrm{A}+$; $F(1,27)=37.48, p<.001$, for Group $\mathrm{A}-; F(1,27)=$ $70.50, p<.001$, for Group A + Context2]. This observation of differential stimulus control after the discrimina- tion training of Phase 1 is not surprising, and it replicates previous results using this preparation (e.g., Arcediano et al., 1996). However, we were uncertain of how the context shift of Phase 2 in Group A + Context 2 and the absence of distractors in all three groups during that phase would influence behavior. A one-way ANOVA on data from the first trial with A during Phase 2 showed no effect for group $[F(2,27)=0.28, p>.5]$. That is, despite the context shift that had been introduced in Group $\mathrm{A}+$ Context 2 , no differences between groups were observed in suppression to the first $A$ trial of Phase 2 ( $M=$ $0.48,0.47$, and 0.47 , for Groups A +, A-, and A + Context2, respectively, with $S E \mathrm{~s}=0.01$ for all three groups). However, the one-way ANOVA on the last Phase 2 trial with A, showed an overall group effect $[F(2,27)=34.74$, $p<.001]$, and planned comparisons showed that Group A - suppressed responding less than did Group A+ $[F(1,27)=54.43, p<.001]$ and Group $\mathrm{A}+$ Context2 $[F(1,27)=52.10, p<.001]$, which did not differ from each other $(p>.5)$ (for groups $\mathrm{A}+, \mathrm{A}-$, and $\mathrm{A}+\mathrm{Con}-$ text2, respectively, $M \mathrm{~s}=0.21,0.49$, and $0.22, S E \mathrm{~s}=$ $0.02,0.005$, and 0.02 ). Thus, despite the absence of distractors during Phase 2 in this experiment, and despite the context shift in Group A+Context2, good stimulus control was still observed during this phase: By the end of Phase 2, Groups A+ and A + Context2, but not Group $\mathrm{A}-$, had learned to suppress responding to A.

Thus, the results of Experiment 2 showed that the interference effect observed in Experiment 1 was not the result of the presence of distractors during treatment (i.e., B and C) or of memory overload. The effect was replicated despite the procedural modifications that we introduced in this experiment (i.e., eliminating the distractors from Phases 1 and 2, and training $X+{ }^{\prime} A-$ in Phase 1 rather than $\mathrm{X}+/ \mathrm{C}-$ ). Moreover, the results of Experiment 2 also showed that $\mathrm{A}-$ training and $\mathrm{A}+$ pairings given in a second context did not produce the interference effect, which is contrary to a memory overload interpretation. Thus, the effect seems to have been due to genuine retrospective competition that occurred in the absence of compound conditioning trials.

However, the way in which we should interpret such competition between individually trained CSs is not yet clear. On the one hand, the behavior of Group A + Context 2 seems to favor an interpretation consistent with the negative activation models. But there are at least two alternative interpretations for the behavior of this group: Perhaps the critical factor in this group was the difference between the context in which $X$ and $A$ were trained (as predicted by the negative activation models), or perhaps the critical factor was the switch between the test context and that in which the A+ pairıngs had occurred. These two possibilities were tested in Experiment 3.

\section{EXPERIMENT 3}

One potential explanation of the results of Experiments 1 and 2 is that each of the associations (i.e., $\mathrm{X}+$ and $\mathrm{A}+$ ) was acquired independently of each other, and neither of 
them was unlearned. Instead, because the A+ association was presumably more strongly activated by the test context (because testing occurred immediately after the Phase 2 pairings in which $\mathrm{A}+$, but not $\mathrm{X}+$, was activated), A successfully competed with $X$ in the activation of the US representation during the test phase. The observation of no impairment in responding to $X$ when the $\mathrm{A}+$ pairings occurred prior to the $\mathrm{X}+$ pairings (Group Forward Competition), when the context was shifted between Phase 2 and testing (Group A+Context2), or when $\mathrm{A}-$, rather than $\mathrm{A}+$ pairings, occurred during Phase 2 (Group $A-$ ) gives some support to this hypothesis. In Group $A+$ Context 2 , the test context no longer resembled the context in which $\mathrm{A}+$ had been trained, and the return to the experimental context of Phase 1 for testing could have produced a reactivation of the $\mathrm{X}+$ association. Alternatively, the context shift that occurred between Phases 1 and 2 in that group, rather than the context shift occurring between Phase 2 and testing, might have been the critical factor, as predicted by the negative activation models (e.g., Dickinson \& Burke, 1996).

Thus, in Experiment 3, we tested whether the critical factor was training $\mathrm{A}+$ in the context in which the $\mathrm{X}+$ pairings had occurred or whether the critical factor was testing $\mathrm{X}$ in the context in which the $\mathrm{A}+$ pairings had occurred. Four groups of subjects received $\mathrm{X}+/ \mathrm{C}-$ training in Context 1 during Phase $1, \mathrm{~A}+$ training during Phase 2 in either Context 1 or Context 2, and then were tested in either Context 1 or Context 2 for responding to $\mathrm{X}$. If the effect were due to the negative activation of $\mathrm{X}$, it should not be observed if the $\mathrm{A}+$ pairings occurred in a context different from that in which $X$ was trained. Alternatively, if the effect were due to A being more strongly activated than $X$ during testing, the effect should be observed if $\mathrm{X}$ is tested in the context in which the $\mathrm{A}+$ pairings occurred, regardless of whether $A$ and $X$ were trained in the same context or in a different context.

\section{Method}

\section{Subjects}

Forty-six undergraduate psychology students volunteered for the experiment. The subjects were randomly assigned in approximately equal number to Groups 1-1-1 $(n=11), 1-1-2(n=11), 1-$ $2-1(n=11)$, and 1-2-2 $(n=13)$. None of the subjects had participated in Experiments 1 or 2.

\section{Apparatus}

The apparatus was identical to that used in Experiment 2, in which the task included two different contexts. However, three different CSs (A, X, and C) were used in this experiment. A and X were yellow and blue, counterbalanced; $C$ was red. Contexts 1 and 2 were the vertical and horizontal contexts used in Experiment 2 (see Figure 1), counterbalanced.

\section{Procedure}

The procedure was identical to that of Experiment 2 except as otherwise noted. Four groups of subjects were used in this experiment. A design summary is presented in Table 3 . The group names refer to the context in which each of the three phases of the experiment was conducted (e.g., Group 1-2-1 received Phase 1 in Con-
Table 3

Design Summary of Experiment 3

\begin{tabular}{lccr}
\hline & \multicolumn{2}{c}{ Treatment } \\
Group & Phase 1 & Phase 2 & Test \\
\hline $1-1-1$ & $(\mathrm{X}+/ \mathrm{C}-)_{1}$ & $(\mathrm{~A}+)_{1}$ & $(\mathrm{X})_{1}$ \\
$1-1-2$ & $(\mathrm{X}+/ \mathrm{C}-)_{1}$ & $(\mathrm{~A}+)_{1}$ & $(\mathrm{X})_{2}$ \\
$1-2-1$ & $(\mathrm{X}+/ \mathrm{C}-)_{1}$ & $(\mathrm{~A}+)_{2}$ & $(\mathrm{X})_{1}$ \\
$1-2-2$ & $(\mathrm{X}+/ \mathrm{C}-)_{1}$ & $(\mathrm{~A}+)_{2}$ & $(\mathrm{X})_{2}$ \\
\hline
\end{tabular}

Note - The four groups received the identical treatment and testing, but we manipulated the contexts ( 1 and 2 ) in which the different phases occurred. Group names refer to the context in which each of the three phases took place for that group. A and X were yellow and blue, counterbalanced; C was red; + represents followed by the US; - represents the absence of the US; the subscripts 1 and 2 refer to Contexts 1 and 2 , respectively.

text 1 , Phase 2 in Context 2 , and the test phase in Context 1). As can be seen in Table 3, the four groups were exposed to identical CS and US manipulations; only the contexts were systematically varied. Phase 1 was conducted in Context 1 for all four groups, and it consisted of 10 presentations of $\mathrm{X}$, which was always followed by the US, and 10 presentations of $\mathrm{C}$, which was never followed by the US. Presentations of $\mathrm{X}+$ and $\mathrm{C}-$ were pseudorandom, with the same randomization used in all four groups. Phase 2 consisted of 10 presentations of A, always followed by the US. No distractor stimulus was presented in this phase. However, unlike in Experiment 2 , the reinforced stimulus of this phase (i.e., A) was different from the nonreinforced stimulus of Phase 1 (i.e., C). The context in which Phase 2 was conducted was Context 1 for half of the subjects (Groups 1-1-1 and 1-1-2), and Context 2 for the other half of the subjects (Groups 1-2-1 and 1-2-2). During training, all CSs were presented during $1 \mathrm{sec}$. The test phase consisted of one presentation of $\mathrm{X}$ and was conducted in Context 1 for Groups 1-11 and 1-2-1 and in Context 2 for Groups 1-1-2 and 1-2-2.

\section{Results and Discussion}

The results of Experiment 3 showed no effect of the context of Phase 2 or of the test context. The interaction of these two contexts, however, appeared critical. Competition occurred when the test context was the same as the Phase $2(\mathrm{~A}+)$ context, but not when those two contexts were different.

An analysis of the number of responses during the 3sec pre-CS interval at test showed similar response rates for all four groups $(M=13.72, S E=0.40$, for Group 1$1-1 ; M=14.09, S E=0.39$, for Group $1-1-2 ; M=13.90$, $S E=0.34$, for Group 1-2-1; $M=14.84, S E=0.40$, for Group 1-2-2) $[F(3,42)=1.69, p>.1]$, thereby indicating that differences during the pre-CS interval were not responsible for the differential suppression to $\mathrm{X}$ at test.

Figure 4 depicts mean suppression ratio to $X$ during the test phase. The predictions of the negative activation models for this experiment were that a main effect for Phase 2 context would occur and that no main effect of test context nor an interaction would be observed. However, as can be seen in Figure 4, the results of this experiment replicated the basic results observed in Experiments 1 and 2 and extended them by showing that the Phase 2 context was not critical. Instead, groups for which the test context was identical to the Phase $2(\mathrm{~A}+)$ context showed weaker suppression to $\mathrm{X}$ than did the groups that 


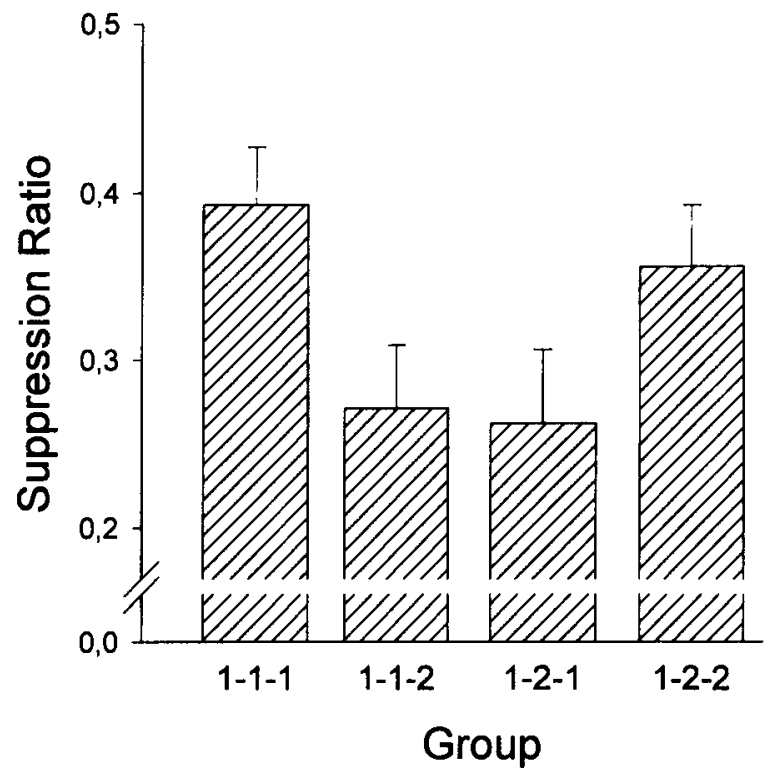

Figure 4. Conditioned responding to the target $\mathrm{CS}, \mathrm{X}$, during the test phase of Experiment 3. The dependent variable was mean suppression ratio. Thus, a lower value indicates stronger conditioning. Error bars represent standard errors of means.

had a test context different from that of Phase 2. These observations were confirmed by a 2 (Phase 2 context: 1 vs. 2) $\times 2$ (test context: 1 vs. 2 ) ANOVA, which yielded a significant Phase 2 context $\times$ test context interaction $[F(1,42)=7.85, p<.01]$ and no main effect for Phase 2 context $[F(1,42)=.35, p>.5]$ or test context $[F(1,42)$ $=.14, p>.5]$. This suggests that unlearning of the $\mathrm{X}$-US association during the $\mathrm{A}+$ pairings of Phase 2 is not a plausible explanation for this effect. Indeed, good responding to $X$ can be obtained regardless of whether the $\mathrm{A}+$ pairings occur in the context in which $\mathrm{X}$ was trained or in a different context, as long as $\mathrm{X}$ is tested in a context different from that in which the $\mathrm{A}+$ pairings had occurred. Instead, competition seems to occur when $\mathrm{X}$ is tested in a context in which the A US association has been recently activated.

Thus, apparently, competition takes place when the competing CS is more strongly activated by the test context than is the target CS. Presumably, one stimulus can be more strongly activated than another stimulus in a given context not only if it has acquired stronger associative strength but also if training with the other stimulus has occurred in a different context or if training with one of the stimuli is more recent than training with the other one. In the present study, A was presumably more strongly activated than $\mathrm{X}$ in the test context, despite $\mathrm{X}$ and $A$ having equivalent associative strength with respect to the US. Apparently, the strong activation of the competing association by the test context makes the other association harder to activate.

\section{GENERAL DISCUSSION}

Contrary to the predictions of most theories of learning, the present research showed that cues can sometimes compete even if they are trained in an individual manner (i.e., not compounded). More specifically, a modification of the backward-blocking procedure in which the blocking and the to-be-blocked cues were not trained in compound (i.e., $\mathrm{X}+$ followed by $\mathrm{A}+$ rather than $\mathrm{AX}+$ followed by $\mathrm{A}+$ ) showed subsequent impaired responding to $X$. This effect did not occur when the $\mathrm{A}+$ pairings occurred before $\mathrm{X}+$ training (Experiment 1 ), when $\mathrm{A}-$, rather than $\mathrm{A}+$, training was given during Phase 2 (Experiment 2), or when the $\mathrm{A}+$ pairings took place during Phase 2 in a context different from that used for $\mathrm{X}$ training and testing (Experiments 2 and 3 ). Moreover, Experiment 3 showed that the critical context was not the context in which the A+ pairings occurred or the context in which the test phase occurred. Instead, the interaction of these two contexts appeared critical in producing the effect: Regardless of whether $X$ was tested in the context in which it had been trained or in a new context, and regardless of whether the A+ pairings of Phase 2 occurred in the same context as or a different context from that in which $\mathrm{X}$ had been trained, weak suppression to $X$ occurred only when the test of $X$ took place in the same context in which the A+ pairings had recently occurred.

We know of no one theory that can explain these effects. The trial order effect observed in Experiment 1 and the contextual effects of Experiments 2 and 3 discard interpretations in terms of blocking by context (e.g., Mackintosh, 1975; Miller \& Matzel, 1988; Pearce \& Hall, 1980; Rescorla \& Wagner, 1972) and statistical effects (e.g., Allan, 1980; Busemeyer et al., 1993; Cheng \& Novick, 1992). On the other hand, the recent revisions of Rescorla and Wagner's (1972) model, which we have here collectively called the negative activation model (Dickinson \& Burke, 1996; Markman, 1989; Tassoni, 1995; Van Hamme \& Wasserman, 1994), predict that each of the A+ trials of Phase 2 should reduce the associative strength of $X$ if the $A+$ pairings occur in the same context as the $\mathrm{X}+$ pairings, and this seemingly provides an explanation for Experiments 1 and 2. However, contrary to the predictions of the negative activation models, the $\mathrm{A}+$ pairings of Phase 2 did not produce unlearning of the associative strength of $\mathrm{X}$ : Experiment 3 showed that good responding to $X$ can still be observed after giving the $\mathrm{A}+$ pairings in the same context in which $\mathrm{X}+$ pairings were given, if $\mathrm{X}$ is tested in a context different from that used for $\mathrm{A}+$ training. Moreover, those models also predict that the $\mathrm{A}+$ pairings of Phase 2 that occurred in a second context should not have affected the associative strength of $X$, because $X$ was not a relevant cue in that second context. However, Experiment 3 showed no main effect of Phase 2 context. 
Instead, the interaction between the Phase 2 context and the test context was what appeared critical, with competition occurring when those two contexts were the same one. Apparently, the strong activation of the A-US association by the test context prevents the activation of the $\mathrm{X}$-US association. This finding invites a reformulation of associative theories. But before attempting any explanation of this finding, it is important to consider what related evidence can be found in the literature.

We are not aware of prior studies specifically testing for competition between individually trained CSs. Although designs similar to ours have frequently been used in the past, they have generally been embedded within designs that were concerned with different issues and that did not test for the possibility of backward competition between the two CSs (e.g., Holland \& Rescorla, 1975). Nevertheless, there are some observations in the literature that could be interpreted as convergent and some that could be interpreted as inconsistent with the present findings. Convergent data can be found in the "miscuing effect" literature (e.g., Lipp, Siddle, \& Dall, 1993; Packer \& Siddle, 1989). The miscuing effect refers to impaired responding that occurs when the US is "miscued" by an inhibitory stimulus (i.e., A + training experienced after $\mathrm{X}+/ \mathrm{A}-$ training produces impaired responding to $X)$. One of our groups in Experiment 2 used just such a design and replicated the miscuing effect. Additionally, Experiment 2 can be regarded as showing that the miscuing effect is context specific. Experiments 1 and 3 , however, did not use miscued trials but used different designs in which a novel stimulus, rather than an inhibitory CS, was paired with the US during Phase 2 . Thus, the effect observed in the present research appears to be more general than that produced by miscued trials. However, the similarities between our findings and the miscuing effect suggest convergent evidence of stimulus competition effects in the absence of compound conditioning.

On the other hand, as noted in the introduction, there are several previous studies that suggest that retrospective revaluation can take place only when there is a within-compound association between the blocking cue and the to-be-blocked cue (e.g., Dickinson \& Burke, 1996; Miller \& Matute, 1996), and this is inconsistent with the present results. In our view, the way in which these two sets of data can be reconciled is by assuming that, on the one hand, within-compound associations are not always necessary for cue competition to occur (as shown in the present research), but that, on the other hand, when within-compound associations can be formed (as was the case in Dickinson \& Burke's and in Miller \& Matute's experiments), they do facilitate stimulus competition. Because the salience of punctuate cues is generally stronger than the salience of contextual cues, the association between two CSs should generally be stronger than the associations between a CS and contextual cues. If, as suggested by the present experiments, competition is due to the activation of the competing CS during testing, it seems reasonable to assume that the ac- tivation of the competing CS during testing should be stronger if punctuate cues, rather than contextual cues, are the ones that activate its representation. This may account for the facilitating role of within-compound associations observed in more traditional cue competition research while allowing for the competitive effects between individually trained cues observed in this research.

Interestingly, a very different line of research has also shown that when organisms acquire two different associations in different phases, the second acquired association interferes with the first association and that, like in the present research, this does not produce unlearning of the first association (e.g., Bouton, 1993; Bouton \& Ricker, 1994; Rescorla, 1996a, 1996b). Indeed, several contextual (or other) posttraining manipulations produced a recovery of the original association in those experiments. This is exactly the same as what we observed, except that, in those studies, the event that changed from one phase to another was usually the outcome (i.e., X-US1 in Phase 1 followed by X-US2 in Phase 2, with US2 being either a different US or the absence of US1), whereas our studies were concerned with changing the first event in the association rather than the outcome (i.e., CS1-US in Phase 1 followed by CS2-US in Phase 2). How critical this difference is we do not know. But, apparently, similar effects can be observed regardless of whether one antecedent event is paired to two different outcomes in different phases or whether one outcome is paired to two different antecedents in different phases.

Although it may be premature to attempt to provide a complete and unified explanation of the experiments involving training with multiple outcomes and those involving training with multiple antecedents, the striking similarities between the two situations are surely worth further attention. Indeed, traditional blocking (i.e., with compound events in Phase 2) has been observed in animals regardless of whether the competing cues were antecedent or subsequent events in the association (EsmorísArranz, Miller, \& Matute, 1997; Rescorla, 1980); the present research shows that antecedents may compete even if they are not trained in compound, and the experiments using training with multiple independent outcomes may be interpreted as showing that multiple outcomes may also compete even if not trained in compound.

Conceptualizing cue competition as something that does not necessarily require the use of compound training and that does not only occur among antecedent events may have the advantage of allowing the integration of apparently unrelated research areas. For example, the present experiments can be regarded as examples of the A B, C-B paradigm in the paired-associate literature, whereas the multiple outcome experiments can be regarded as examples of the A-B, A-C paradigm, both of which are examples of interference paradigms (see, e.g., Underwood, 1966). In the A-B, C-B paradigm (the present research), the subject first learns an antecedent outcome association (A-B) and then learns to associate the same outcome $(B)$ to a different antecedent $(C)$. In 
the A-B, A-C paradigm (multiple outcomes), the subject first acquires an antecedent outcome association (A-B) and then learns to associate the same antecedent (A) to a different outcome (C). Both paradigms produce interference, thereby inviting a unified explanation.

One important factor that emerges from the present research as well as from experiments dealing with multiple outcomes (e.g., Bouton, 1993; Bouton \& Ricker, 1994; Rescorla 1996a, 1996b), or even from traditional (compounded) cue competition studies (e.g., Miller \& Matzel, 1988), is that competition between associations probably takes place at the retrieval, rather than the acquisition, stage. However, although several theories have been developed that emphasize postacquisition processes both within the multiple outcomes and within the multiple antecedents paradigms, none of them appears capable of providing a complete explanation for the present results. For example, Miller and Matzel correctly predict that competition takes place during retrieval, but they do not predict competition between individually trained CSs (although Miller \& Matzel's prediction of backward blocking by context may seem, at first glance, an alternative interpretation for this research, this explanation would predict [1] equal backward and forward blocking by context - a result that is contrary to Experiment 1 and [2] backward blocking by context in Group 1-1-2 in Experiment 3 rather than in our critical group throughout the three experiments [e.g., Group 1-1-1], because, in Group 1-1-1, both the training context and X are physically present during testing, and, thus, no competition between them should be expected [if anything, some summation should be expected in Group 1-1-1]).

Similarly, Bouton (e.g., Bouton, 1994) predicts competition between independent outcomes during retrieval but does not predict competition between independent CSs. According to Bouton, if one CS becomes associated to two different outcomes in different phases, none of those associations is unlearned, but the CS is not able to retrieve both outcomes simultaneously. In those cases, the CS will predict one or the other outcome as a function of the context in which retrieval occurs (with the context for each phase being either a physically distinct context or the temporal context in which it occurred). If retrieval occurs in the temporal or physical context of Phase 1, the CS predicts Outcome 1; if it occurs in the context of Phase 2, the CS predicts Outcome 2.

Extending this view, the temporal or physical context in which retrieval occurred in the present research could have activated the competing association (A-US), which could then have competed with the activation of the target association (X-US). This is consistent with our observation, throughout the three experiments, that competition occurred only when $X$ was tested in the same temporal or physical context in which the A US pairings had occurred. Apparently, there is a limit in the total associative connections that can be simultaneously activated from or to a given event representation. In this way, competition among associations can be regarded as an emergent property of the associative structure. That is, competition among intact associations can take place when several of them are simultaneously connected to (or from) the representation of the same event, and one of those associations either (1) is more strongly activated than the other one or (2) has a stronger associative strength than the other one (the basis of most traditional forms of cue competition).

Nevertheless, this alone does not explain why the activation of the A-US association fails to elicit a response. One possibility is that the representation of an event that is activated through an associative connection is different from the representation of an event that is physically present (e.g., Miller \& Matzel, 1988; Wagner, 1981 ). If the A-US association is strongly activated by the test context, the subjects should expect the US to occur after $\mathrm{A}$ in that context, but only if $\mathrm{A}$ is presented (or, at least, immediately expected). However, if the subjects note that the CS that is present is a different one (X), then they would have relatively little expectation of the US.

Despite these speculations, the important point of this research is that responding to a target CS that was paired to a US during Phase 1 can be impaired if a new CS is paired to the same US during Phase 2, even though the two CSs had never been trained in compound. Thus, compound training is not always necessary for the occurrence of stimulus competition. Additionally, because cue competition has traditionally been studied in compound stimulus situations, it has been regarded as a "special" situation that is different from extinction, counterconditioning, and other paradigms that also produce interference of one association over another one but that generally use elemental training. The present research, by showing competition between individually trained CSs, can more readily make the connection between the cue competition literature and other research areas that also show associative interference. Although it may be premature to state that the same processes are involved in all of the interference paradigms, entertaining this possibility may eventually lead to a unified theory of learning and retrieval capable of integrating research on the various interference paradigms.

\section{REFERENCES}

AI.L AN, L. G (1980). A note on measurement of contingency between two binary variables in judgment tasks. Bulletin of the Psychonomic Society, 15, 147-149

arcediano, F., Matl Te, H., \& Miller, R, R (1997). Blocking of Pavlovian conditioning in humans. Learning \& Motivation, 28, 188 199

Arcediano, F., Ortega, N., \& Matl te, H (1996). A behavioural preparation for the study of human Pavlovian conditioning Quar terly Journal of Experimental Psychology, 49B, 270-283.

Bol ToN, M. E. (1993) Context, time, and memory retrieval in the in terference paradıgms of Pavlovian learnıng. Psychological Bulletin, 114, 80-99

BorTON, M. E. (1994), (ontext, ambiguity, and classical conditioning Current Directions in Psychological Science, 3, 49-53

Bolton, M. E., \& Ricker, S. T. (1994) Renewal of extinguished re 
sponding in a second context. Animal Learning \& Behavior, 22 317-324.

Busemeyer, J. R., Myung, I. J., \& MCDaniel, M. A. (1993). Cue competition effects: Theoretical implications for adaptive network learning models. Psychological Science, 4, 196-202.

Cheng, P. W., \& Novick, L. R. (1992). Covariation in natural causal induction. Psychological Review, 99, 365-382.

Dickinson, A., \& BURKE, J. (1996). Withın-compound associations mediate the retrospective revaluation of causality judgments. Quarterly Journal of Experimental Psychology, 49B, 60-80.

Esmorís-Arranz, F. J., Mill.er, R. R., \& Matute, H. (1997). Blocking of subsequent and antecedent events. Journal of Experimental Psychology: Animal Behavior Processes, 23, 145-156.

Holland, P. C., \& Rescorla, R. A. (1975). The effect of two ways of devaluing the unconditioned stımulus after first- and second-order appetitive conditioning. Journal of Experimental Psychology: Animal Behavior Processes, 1, 355-363.

KAMIN, L. J. (1968). "Attention-like" processes in classical conditionIng. In M. R. Jones (Ed.), Miami symposium on the prediction of behavior: Aversive stimulation (pp. 9-31). Miami: University of Miamı Press.

LIPP, O V., SidDle, D. A. T., \& DALL, P. J. (1993). Effects of miscuing on Pavlovian conditioned responding and on probe reaction time. Australian Journal of Psychology, 45, 161-167.

MACKINTOSH, N. J. (1975). A theory of attention: Varıations in the associability of stımuli with reınforcement. Psychological Review, 82, 276-298.

MARKMAN, A. B. (1989). LMS rules and the inverse base-rate effect: Comment on Gluck and Bower (1988). Journal of Experimental Psychology. General, 118, 417-421.

MilleR, R. R., \& MATUTE, H. (1996). Biological significance in forward and backward blocking. Resolution of a discrepancy between animal conditioning and human causal judgment. Journal of Experimental Psychology' General, 125, 370-386.

Miller, R. R., \& MATZEL, L. D. (1988). The comparator hypothesis: A response rule for the expression of associatıons. In G. H. Bower (Ed.), The psychology of learning and motivation, (Vol. 22, pp. 5192). San Diego: Academic Press.

PACKer, J. S., \& SidDle, D. A. T. (1989). Stimulus miscuing, electrodermal activity and the allocation of processing resources. Psychophysiology, 26, 192-200.
Pearce, J. M., \& Hall, G. (1980). A model for Pavlovian learning: Variations in the effectiveness of conditioned but not of uncond1tioned stimuli. Psychological Review, 87, 532-552.

ResCorla, R. A. (1980). Pavlovian second-order conditioning. Hillsdale, NJ: Erlbaum.

Rescorla, R. A. (1996a). Preservation of Pavlovian associations through extinction. Quarterly Journal of Experimental Psychology, 49B, 245-258.

RESCORLA, R. A. (1996b). Spontaneous recovery after training with multiple outcomes. Animal Learning \& Behavior, 24, 11-18.

REsCoRLA, R. A., \& WAGNER, A. R. (1972). A theory of Pavlovian conditioning: Variations in the effectiveness of reinforcement and nonreinforcement. In A. H. Black \& W. F. Prokasy (Eds.), Classical conditioning II. Current research and theory (pp. 64-99). New York: Appleton-Century-Crofts.

SHANKs, D. R. (1985). Forward and backward blocking in human contingency judgment. Quarterly Journal of Experimental Psychology, 37B, 1-21.

Shanks, D. R., \& Dickinson, A. (1987). Associative accounts of causality judgment. In G. H. Bower (Ed.), The psychology of learning and motivation (Vol. 21, pp. 229-261). San Diego: Academic Press.

TAssoni, C. J. (1995). The least mean squares network with information coding: A model of cue learning. Journal of Experimental Psychology' Learning, Memory, \& Cognition, 21, 193-204.

UNDERWOOD, B. J. (1966). Experimental psychology (2nd ed.). New York: Appleton-Century-Crofts.

Van Hamme, L. J., \& Wasserman, E. A. (1994) Cue competition in causality judgments: The role of nonpresentation of compound stimulus elements. Learning \& Motivation, 25, 127-151.

WAGNER, A. R. (1981). SOP: A model of automatic memory processing in anımal behavior. In N. E. Spear \& R. R. Miller (Eds.), Information processing in animals: Memory mechanisms (pp. 5-47). Hillsdale, NJ: Erlbaum.

Wagner, A. R., Logan, F. A., Haberlandt, K., \& Price, T. (1968). Stimulus selection and a "modified continuity theory." Journal of Experimental Psychology, 76, 171-180.

(Manuscript recelved May 6, 1996; revision accepted for publication June 27, 1997) 